Clinical Study

\title{
Efficacy of Bilateral Transversus Abdominis Plane and Ilioinguinal-Iliohypogastric Nerve Blocks for Postcaesarean Delivery Pain Relief under Spinal Anesthesia
}

\author{
Seid Adem Ahemed, Zewditu Abdissa Denu (D), Habtamu Getinet Kassahun, and \\ Demeke Yilikal Fentie \\ Department of Anesthesia, College of Medicine and Health Sciences, University of Gondar, Gondar, Ethiopia \\ Correspondence should be addressed to Zewditu Abdissa Denu; zewditudenuabdissa@gmail.com
}

Received 15 August 2017; Revised 20 November 2017; Accepted 28 November 2017; Published 21 January 2018

Academic Editor: Ronald G. Pearl

Copyright (C) 2018 Seid Adem Ahemed et al. This is an open access article distributed under the Creative Commons Attribution License, which permits unrestricted use, distribution, and reproduction in any medium, provided the original work is properly cited.

\begin{abstract}
Background. Caesarean delivery can be associated with considerable postoperative pain. While the benefits of transversus abdominis plane (TAP) and ilioinguinal-iliohypogastric (II-IH) nerve blocks on pain after caesarean delivery via Pfannenstiel incision have been demonstrated, no enough investigations on the comparison of these blocks on pain after caesarean delivery have been conducted in our setup. Method. An institutional-based prospective observational cohort study was conducted to compare the analgesic efficacy of those blocks. We observed 102 postoperative parturients. The outcome measure was the severity of pain measured using a numeric rating scale. Result. Twenty-four hours after surgery, the NRS score at rest was $(0.90 \pm 0.80)$ versus $(0.67 \pm 0.58)$ and at movement $(1.2 \pm 1.07)$ versus $(0.88 \pm 0.76)$ for the TAP and II-IH groups, respectively. Twenty-four hours after surgery, the mean tramadol consumption was $(55.45 \pm 30.51)$ versus $(37.27 \pm 27.09) \mathrm{mg}$ in TAP and II-IH groups, respectively $(p=0.009)$. The mean first analgesic requirement time was also prolonged in the II-IH group. Conclusion and Recommendations. There was no statically significant difference between TAP and II-IH blocks regarding postoperative pain score, but the II-IH block significantly reduced the total tramadol consumption and prolonged the time to first analgesic request than TAP. Thus, we recommend the II-IH nerve block.
\end{abstract}

\section{Introduction}

Pain management is crucially important in the postoperative period as it increases patient comfort and satisfaction [1]. Caesarean delivery (CD) has been one of the most frequently performed major surgical interventions and causes severe postoperative pain [2]. Caesarean delivery and subsequent manipulation performed through Pfannenstiel incision are associated commonly with a significant degree of pain in the postoperative period; $79 \%$ of women experience pain at the incision site that can last for up to 2 months [3].

Inadequate postoperative analgesia is one of the most common causes for poor patient satisfaction following caesarean delivery $[3,4]$.

Childbirth is an emotion-filled event, and the mother wants to bond with her newborn as early as possible.
Inadequate postoperative pain relief after $\mathrm{CD}$ can negatively impact ambulation, breastfeeding, and even maternal bonding $[2,5]$.

Poor pain control in the postoperative period can lead to chronic pain syndromes and poor quality of life $[2,5]$.

The provision of effective postoperative analgesia is a key to facilitate early mobilization of the mother, infant care, and prevention of postoperative morbidity. Improvement in postoperative analgesia may not only increase patient satisfaction but also diminish the duration of hospital stay and reduce the risk of complications $[6,7]$.

The ideal form of postoperative analgesia is unknown, but many procedures are carried out under spinal anesthesia, and currently, opioids are commonly used for relief of postoperative pain after caesarean section, either by 
intrathecal administration prior to section or by postoperative parenteral administration as a component of multimodal analgesia during the postoperative period $[6,8]$.

Even if opioids are available to be administered via the spinal or systemic route, they had adverse effects such as nausea, vomiting, sedation, itching, and risk of delayed maternal respiratory depression, all of which reduce overall patient satisfaction $[2,3,8]$.

Additionally, these opioid-related adverse effects can produce other problems for new mothers such as delayed initiation of breastfeeding and impairment of mother/infant bonding [3].

An ideal method of pain relief after caesarean delivery should be cost-effective, safe for the mother, require minimal monitoring, and use drugs that are not secreted into breast milk. Moreover, the mother should not be sedated by the drugs that prevent her from moving freely and caring for the newborn.

Minor side effects, such as pruritus and shivering, may interfere with care of the newborn, leading to less maternal satisfaction. Drug availability, maternal health conditions, patient preferences, and availability of medical expertise and trained support staff also play a role in choice of the analgesic method.

Many scholars have been studying to find the safest and effective way of interventions for postoperative CD pain management, and they suggest methods like opioid or local anesthetic skin infiltration, epidural analgesia, intrathecal or intravenous opioids, and abdominal field blocks like TAP and II-IH.

Among the above-listed ways of pain management, intravenous opioids and regional nerve blocks are the mainstay of treatment for postcaesarean pain here in the study area.

Epidural analgesia, which is the gold standard for control of labour pain and postoperative pain, is not commonly practiced in our setup due to lack of the epidural kit.

Abdominal field blocks like TAP and II-IH are the mainstay of treatment for postcaesarean pain for both the midline and Pfannenstiel incision because of the opioid sparing effect, prolonged pain relief, and technical simplicity, and also, it does not need repeated injection for optimal pain relief $[3,9]$.

TAP and II-IH nerve blocks are well known and easy to perform, and currently, these blocks are done in the study area for post-CD pain management.

There are no enough data concerning the efficacy of TAP versus II-IH nerve blocks in the management of postoperative pain in parturients undergoing caesarean section.

Most of the studies that have been done to determine the efficacy of those blocks in post-CD pain management are done in western countries, but there is no published literature in Ethiopia.

The presence of racial, cultural, genetic, and sociodemographic differences in the perception of pain has been well documented [10, 11].

There is also controversy regarding the efficacy of the two blocks $[12,13]$, so comparing the effectiveness of TAP blocks with that of II-IH nerve blocks will help us to have a best practice to the study area, and knowing the efficacy of these blocks will allow anesthetists to choose the most effective one to manage postoperative CD pain.

The aim of this study was to compare the efficacy of the TAP block and II-IH block in controlling postcaesarean section pain.

\section{Methods}

An institutional-based observational cohort study was conducted from April 1 to May 30, 2017, at Gondar University Teaching Hospital after we secured ethical approval from the University of Gondar Ethical Review Board. The minimum sample size calculated for this study was 102, and the sample size calculation was done based on the two population proportion principles:

$$
\frac{p_{1}\left(1-p_{1}\right)+p_{2}\left(1-p_{2}\right)}{\left(p_{2}-p_{1}\right)^{2}} \times f(\alpha, \beta) .
$$

(i) Hence, the incidence of moderate-to-severe pain after CD without intervention was $87 \%$, and we got pain reduction after clients received bilateral TAP and II-IH blocks $40 \%$ and $70 \%$, respectively. And we calculated $p_{1}$ by reducing $40 \%$ of $87 \%$ from $87 \%$ $\left(p_{1}=0.87-0.348=0.522\right)$ and $p_{2}$ by reducing $70 \%$ of $87 \%$ from $87 \%(0.87-0.69=0.261)$ since we need only pain reduction after the block from the incidence of pain $(87 \%)$ by taking $\dot{f}(\alpha, \beta)=7.85$ with a power of $80 \%$ and 0.05 significance.

(ii) Since $f(\alpha, \beta)=7.85$ or 10.5 for $80 \%$ or $90 \%$ power, respectively, with $5 \%$ significance, the significance (risk of type I error) is almost always set at $5 \%$.

So per group, we have 51 participants.

We included ASA I and ASA II patients. Finally, we selected every consecutive parturient for whom the abovementioned nerve blocks were done and who also volunteered to give consent to participate in the study till the required sample is achieved. Our primary outcome measure was the severity of pain which was measured using the numeric rating scale. The secondary outcomes were the total analgesic consumption and time for the first analgesic request. As to the data collection procedure, two trained anesthetists collect all the required information based on the checklist prepared in English. The investigators had no power to decide which type of block would be given for the mother (only the responsible anesthesiologist had this right, i.e., he/she did the block as he/she wishes, either TAP or II-IH).

But the investigator stayed in the operating theater and saw the type of block that the responsible anesthesiologist had done and put the code on the chart. The type of block was not clearly recorded on the chart except the code so that data collectors are blinded to the type of block done for each mother.

The relative proportion of these blocks in our institution looks equal $(1: 1)$ because everybody is doing these blocks randomly as they wish for transverse incision, but for vertical incision, they do only TAP. 
The block was done by using the landmark technique for both types, and a total of $32 \mathrm{ml}$ of $0.25 \%$ bupivacaine for IIIH block ( $8 \mathrm{ml}$ in each side) and $40 \mathrm{ml}$ of $0.25 \%$ bupivacaine for TAP block $(20 \mathrm{ml}$ in each side) were given.

Pain assessment was performed at $0 \mathrm{hr}, 4 \mathrm{hr}, 6 \mathrm{hr}, 8 \mathrm{hr}$, $12 \mathrm{hr}$, and $24 \mathrm{hr}$ in the ward by blinded data collectors who were unaware of the type of the nerve block done. And the total analgesic consumption within 24 hours was also recorded.

Data were coded, entered, cleaned, and cross-checked with SPSS version 20 statistical package. The data were tested for normality using the Shapiro-Wilk normality test. Normally distributed data were analyzed using Student's $t$-test.

All data other than categorical parameters were analyzed using Student's $t$-test.

The comparisons of categorical parameters were analyzed using the chi-square test or Fisher's exact test as required and expressed in $\%$ and numbers. Data were presented as mean \pm SD. $p$ value $<0.05$ was considered statistically significant.

\section{Results}

A total of hundred and two clients were enrolled in the current study with a response rate of $100 \%$. The age of participants was 26.98 with a standard deviation of 2.4 years. Assessment of the ASA physical status showed that $78 \%$ of the TAP and $76 \%$ of the II-IH groups were ASA I and $21.56 \%$ of the TAP and $23.5 \%$ of the II-IH groups were ASA II (Table 1).

Postoperative vital signs (postoperative pulse rate and mean arterial blood pressure) were comparable between the two groups (Tables 2 and 3 ).

\subsection{Postoperative Pain Scores using Numerical Rating} Scale. With regard to the postoperative pain score, there was no difference between the two groups. We assessed the pain score at rest, on coughing, and at movement. The result shows no statistically significant difference between the two groups (Tables 4 and 5).

The mean tramadol consumption for the TAP group was 52.45 with a standard deviation of 30.5 , and for the II IH group, it was $37.25 \pm 27.09 \mathrm{mg}$; the mean first analgesic consumption time in this study was $10.71 \pm 7.67 \mathrm{hr}$ for the TAP group and $14.09 \pm 8.20 \mathrm{hr}$ for the II-IH group, with a $p$ value of 0.03 (Table 6)

\section{Discussion}

We found that there was no statistically significant difference between TAP and II-IH blocks in the numeric pain rating score both at rest and at movement for the first postoperative 24 hours, but the II-IH nerve block significantly reduced total tramadol consumption and prolonged the time for the first analgesic request.

Studies comparing the two blocks are rare, so we compare our results separately for each block.
TABle 1: Sociodemographic and other characteristics of study participants from April 1 to May 30, 2017, in Northwest Ethiopia.

\begin{tabular}{lccc}
\hline Character & TAP $(n=51)$ & II-IH $(n=51)$ & $p$ value \\
\hline Age (years) & $27.27 \pm 2.88$ & $26.69 \pm 1.79$ & 0.219 \\
Height (meter) & $1.67 \pm 0.04$ & $1.65 \pm 0.04$ & 0.077 \\
Weight $(\mathrm{kg})$ & $63.10 \pm 7.69$ & $64.88 \pm 9.45$ & 0.299 \\
BMI $\left(\mathrm{kg} / \mathrm{m}^{2}\right)$ & $22.63 \pm 2.01$ & $23.29 \pm 2.97$ & 0.192 \\
ASA I & $40(78.51 \%)$ & $39(76.34 \%)$ & 0.814 \\
ASA II & $11(21.56 \%)$ & $12(23.52 \%)$ & \\
Parity & & & \\
Nulliparous & $28(54.90 \%)$ & $27(52.90 \%)$ & 0.843 \\
Multiparous & $23(45.09 \%)$ & $24(47.05 \%)$ & \\
Number of previous c/s & & & \\
0 & $39(76.47 \%)$ & $38(74.50 \%)$ & \\
1 & $11(21.56 \%)$ & $9(17.64 \%)$ & 0.529 \\
2 & $1(1.96 \%)$ & $3(5.88 \%)$ & \\
3 & $0(0 \%)$ & $1(1.96 \%)$ & \\
Level of sensory block & & & \\
T6-T4 & $7(13.72 \%)$ & $8(15.68 \%)$ & 0.780 \\
T7-T10 & $44(86.27 \%)$ & $43(84.31 \%)$ & \\
Duration of surgery (min) & $45.29 \pm 9.24$ & $48.33 \pm 7.85$ & 0.077 \\
\hline
\end{tabular}

TABLE 2: Postoperative pulse rate (beats per minute) in both groups who underwent caesarean delivery under spinal anesthesia in Gondar University Hospital from April 1 to May 30, 2017, in Northwest Ethiopia.

\begin{tabular}{lccc}
\hline Postoperative time & $\begin{array}{c}\text { TAP group } \\
(n=51)\end{array}$ & $\begin{array}{c}\text { II-IH group } \\
(n=51)\end{array}$ & $p$ value \\
\hline 0 hour & $77.29 \pm 4.11$ & $75.20 \pm 7.91$ & 0.96 \\
4 hours & $76.00 \pm 5.21$ & $77.27 \pm 5.37$ & 0.22 \\
6 hours & $76.02 \pm 5.98$ & $77.35 \pm 2.99$ & 0.15 \\
8 hours & $76.04 \pm 6.09$ & $76.16 \pm 6.76$ & 0.92 \\
12 hours & $76.41 \pm 3.00$ & $76.53 \pm 2.36$ & 0.82 \\
24 hours & $76.53 \pm 3.85$ & $75.16 \pm 3.63$ & 0.06 \\
\hline
\end{tabular}

Data are mean \pm SD.

TABLe 3: Postoperative mean arterial blood pressure $(\mathrm{mmHg})$ in both groups who underwent caesarean delivery under spinal anesthesia in Gondar University Hospital from April 1 to May 30, 2017, in Northwest Ethiopia.

\begin{tabular}{lccc}
\hline Postoperative time & $\begin{array}{c}\text { TAP group } \\
(n=51)\end{array}$ & $\begin{array}{c}\text { II-IH group } \\
(n=51)\end{array}$ & $p$ value \\
\hline 0 hour & $78.43 \pm 5.45$ & $76.42 \pm 5.59$ & 0.06 \\
4 hours & $84.33 \pm 8.29$ & $84.25 \pm 7.62$ & 0.96 \\
6 hours & $85.05 \pm 6.18$ & $85.01 \pm 6.47$ & 0.97 \\
8 hours & $87.23 \pm 5.43$ & $88.08 \pm 3.88$ & 0.36 \\
12 hours & $84.77 \pm 6.66$ & $86.22 \pm 6.02$ & 0.25 \\
24 hours & $89.03 \pm 3.24$ & $89.41 \pm 3.84$ & 0.58 \\
\hline
\end{tabular}

Data are mean \pm SD 
TABle 4: Postoperative NRS scores at rest over the first 24 postoperative hours among parturients who underwent caesarean delivery under spinal anesthesia in Gondar University Hospital from April 1 to May 30, 2017, in Northwest Ethiopia.

\begin{tabular}{lccc}
\hline Character & TAP group & II-IH group & $p$ value \\
\hline NRS score at $0 \mathrm{hr}$ & 0.00 & 0.00 & \\
NRS score at $4 \mathrm{hr}$ & $0.69 \pm 1.46$ & $0.41 \pm 1.00$ & 0.27 \\
NRS score at $6 \mathrm{hr}$ & $0.67 \pm 0.136$ & $0.41 \pm 1.09$ & 0.30 \\
NRS score at $8 \mathrm{hr}$ & $0.65 \pm 1.18$ & $0.35 \pm 0.79$ & 0.14 \\
NRS score at $12 \mathrm{hr}$ & $0.49 \pm 0.857$ & $0.16 \pm 0.46$ & 0.22 \\
NRS score at $24 \mathrm{hr}$ & $0.90 \pm 0.80$ & $0.67 \pm 0.58$ & 0.95 \\
\hline
\end{tabular}

Data are mean \pm SD.

TABLE 5: Postoperative NRS scores at movement or on coughing in the postoperative 24 hours of parturients who underwent caesarean delivery under spinal anesthesia in Gondar University Hospital from April 1 to May 30, 2017, in Northwest Ethiopia.

\begin{tabular}{lccc}
\hline Character & TAP group & II-IH group & $p$ value \\
\hline NRS score at $0 \mathrm{hr}$ & 0.00 & 0.00 & \\
NRS score at $4 \mathrm{hr}$ & $1.63 \pm 2.12$ & $0.96 \pm 1.52$ & 0.07 \\
NRS score at $6 \mathrm{hr}$ & $1.84 \pm 1.88$ & $1.24 \pm 1.53$ & 0.07 \\
NRS score at $8 \mathrm{hr}$ & $1.39 \pm 1.53$ & $1.00 \pm 1.09$ & 0.14 \\
NRS score at $12 \mathrm{hr}$ & $1.39 \pm 1.49$ & $0.92 \pm 1.197$ & 0.08 \\
NRS score at $24 \mathrm{hr}$ & $1.20 \pm 1.07$ & $0.88 \pm 0.76$ & 0.09 \\
\hline
\end{tabular}

Data are mean \pm SD.

TABle 6: Postoperative total opioid consumption and first analgesic request time over the first 24 postoperative hours of parturients who underwent caesarean delivery under spinal anesthesia in Gondar University Hospital from April 1 to May 30, 2017, in Northwest Ethiopia.

\begin{tabular}{lccc}
\hline Character & TAP group & II-IH group & $p$ value \\
\hline $\begin{array}{l}\text { Total tramadol } \\
\text { consumption }(\mathrm{mg})\end{array}$ & $52.45 \pm 30.51$ & $37.25 \pm 27.09$ & 0.009 \\
$\begin{array}{l}\text { First analgesic } \\
\text { request time }(\mathrm{hr})\end{array}$ & $10.71 \pm 7.67$ & $14.09 \pm 8.20 \mathrm{hr}$ & 0.03 \\
\hline
\end{tabular}

Data are mean \pm SD.

Our result was comparable with the randomized controlled study done in Russia which showed that there was no statistically significant VAS (visual analogue score) difference between TAP and II-IH blocks after caesarean delivery via Pfannenstiel incision within 24 hours postoperatively [14].

A randomized comparative study done in New Zealand showed that the II-IH nerve block reduced the pain score significantly and postoperative total tramadol consumption $(p=0.03)$ than the TAP block after inguinal surgery [12]. This is consistent with our result regarding tramadol consumption.

A systematic review and meta-analysis done by Abdallah et al. in Canada demonstrated that the TAP block enhances analgesia after caesarean delivery with detectable analgesic effects for the entire 24 hours [5].
Another review and meta-analysis done by Mishriky et al. concluded that the TAP block improved postoperative analgesia and reduced the pain score in women undergoing CD [4]. These two are in agreement with our results.

A meta-analysis done by Champaneria et al. in 2016 showed that the TAP block provided effective analgesia and reduced the postoperative pain score after caesarean section [15]. This is comparable to our result.

Our result is comparable with a randomized control trial study done in Saudi Arabia that showed the NRS score was significantly lower in the TAP group than the control up to $24 \mathrm{hr}$ both at rest and at movement after caesarean delivery via Pfannenstiel incision [15].

On the other hand, a study done by Sakalli et al. showed that the II-IH nerve block decreased the mean VAS score both at rest and at movement within 24 hours after CD [2]. This is comparable with our finding.

Similarly, a study done in Jordan showed a significant reduction in the mean VAS score after the II-IH nerve block when compared with the placebo group in parturients who underwent caesarean delivery under general anesthesia [16, 17].

Our study demonstrated that II-IH reduced the NRS pain score which is consistent with a study done by Bunting and McConachie and Ganta and colleagues, who analyzed the mean VAS score, and they found it to be less with the IIIH block as compared with the placebo group in parturients who underwent caesarean delivery [18]. A study of Bell and colleagues also demonstrated that the VAS score was reduced with the II IH nerve block [3].

A study done in Turkey by Yucel and colleagues showed that the II-IH nerve block reduced the VAS score for the first $24 \mathrm{hr}$ postoperatively than the control group. This is comparable with the current study [19].

In this study, the mean time for the first analgesic request was significantly prolonged in the II-IH group $(p=0.03)$. This is consistent with the finding of the previous comparative study done in Russia which showed that the II-IH block prolonged the time to first analgesic requirement in a statistically significant fashion than the TAP block following CD [14].

We found that the total amount of tramadol consumption over the first 24 -hour postoperative time was lower in the II-IH group than that in the TAP group. This result is comparable with the previous study [14]. One study done in New Zealand was also in line with this study [12].

Our finding was also comparable with the studies conducted by Yucel et al. and Naghshineh et al. where they have found that postoperative analgesic consumption was significantly lower in the parturients who received the II-IH block as compared with the control group [20].

\section{Conclusion and Recommendation}

There was no statistically significant difference between TAP and II-IH nerve blocks regarding the postoperative pain score in each time point both at rest and at movement, but the II-IH block significantly reduced total tramadol 
consumption and prolonged the time to first analgesic request than TAP.

We recommend the II-IH nerve block for postcaesarean delivery pain management via Pfannenstiel incision.

\section{Conflicts of Interest}

The authors declare no conflicts of interest.

\section{Authors' Contributions}

All authors contributed equally to this work.

\section{Acknowledgments}

The authors would like to acknowledge the University of Gondar, Research and Community Service Vice President Office, for their support. The authors would also like to appreciate data collectors, our participants, and Gondar University Hospital.

\section{References}

[1] L. Eslamian, M. Kabiri-Nasab, M. Agha-Husseini, O. Azimaraghi, G. Barzin, and A. Movafegh, "Adding sufentanil to TAP block hyperbaric bupivacaine decreases post-cesarean delivery morphine consumption," Acta medica Iranica, vol. 54, no. 3, pp. 185-190, 2016.

[2] M. Sakalli, A. Ceyhan, H. Y. Uysal, I. Yazici, and H. Başar, "The efficacy of ilioinguinal and iliohypogastric nerve block for postoperative pain after caesarean section," Journal of Research in Medical Sciences, vol. 15, no. 1, pp. 6-13, 2010.

[3] E. A. Bell, B. P. Jones, A. J. Olufolabi et al., "Iliohypogastricilioinguinal peripheral nerve block for post-Cesarean delivery analgesia decreases morphine use but not opioid-related side effects," Canadian Journal of Anaesthesia, vol. 49, no. 7, pp. 694-700, 2002.

[4] B. M. Mishriky, R. B. George, and A. S. Habib, "Transversus abdominis plane block for analgesia after Cesarean delivery: a systematic review and meta-analysis," Canadian Journal of Anesthesia, vol. 59, no. 8, pp. 766-778, 2012.

[5] F. W. Abdallah, S. H. Halpern, and C. B. Margarido, "Transversus abdominis plane block for postoperative analgesia after Caesarean delivery performed under spinal anaesthesia? A systematic review and meta-analysis," British Journal of Anaesthesia, vol. 109, no. 5, pp. 679-687, 2012.

[6] N. Nguyen, A. Landais, A. Barbaryan et al., "Analgesic efficacy of Pfannenstiel incision infiltration with ropivacaine 7.5 $\mathrm{mg} / \mathrm{mL}$ for caesarean section," Anesthesiology Research and Practice, vol. 2010, pp. 1-7, 2010.

[7] L. Buhagiar, O. A. Cassar, M. P. Brincat et al., "Predictors of post-caesarean section pain and analgesic consumption," Journal of Anaesthesiology Clinical Pharmacology, vol. 27, no. 2, p. 185, 2011.

[8] X. Li, M. Zhou, X. Shi, et al., "Local anaesthetic wound infiltration used for caesarean section pain relief: a metaanalysis," International Journal of Clinical and Experimental Medicine, vol. 8, no. 6, pp. 10213-10224, 2015.

[9] W. Mei, C. Jin, L. Feng et al., "Bilateral ultrasound-guided transversus abdominis plane block combined with ilioinguinal-iliohypogastric nerve block for cesarean delivery anesthesia," Anesthesia and Analgesia, vol. 113, no. 1, pp. 134-137, 2011.
[10] D. Belavy, P. Cowlishaw, M. Howes, and F. Phillips, "Ultrasound-guided transversus abdominis plane block for analgesia after caesarean delivery," British Journal of Anaesthesia, vol. 103, no. 5, pp. 726-730, 2009.

[11] M. C. Vallejo, T. L. Steen, B. T. Cobb, et al., "Efficacy of the bilateral ilioinguinal-iliohypogastric block with intrathecal morphine for postoperative cesarean delivery analgesia," The Scientific World Journal, vol. 2012, Article ID 107316, 6 pages, 2012.

[12] M. J. Fredrickson, C. Paine, and J. Hamill, "Improved analgesia with the ilioinguinal block compared to the transversus abdominis plane block after pediatric inguinal surgery: a prospective randomized trial," Pediatric Anesthesia, vol. 20, no. 11, pp. 1022-1027, 2010.

[13] C. Aveline, H. Le Hetet, A. Le Roux et al., "Comparison between ultrasound-guided transversus abdominis plane and conventional ilioinguinal/iliohypogastric nerve blocks for day-case open inguinal hernia repair," British Journal of Anaesthesia, vol. 106, no. 3, pp. 380-386, 2011.

[14] A. E. Bessmertnyj, E. E Antipin, D. N Uvarov, S. V Sedyh, and E. V Nedashkovsky, "Comparison of the effectiveness of ilioinguinal-iliohypogastric blockade and transversus abdominis plane block for analgesia after cesarean section," Anesteziologiia i Reanimatologiia, vol. 60, no. 2, pp. 51-54, 2015.

[15] R. Champaneria, L. Shah, M. J. Wilson, and J. P. Daniels, "Clinical effectiveness of transversus abdominis plane (TAP) blocks for pain relief after caesarean section: a meta-analysis," International Journal of Obstetric Anesthesia, vol. 28, pp. 45-60, 2016.

[16] G. Al-Dehayat and M. Al-Momany, "Ilioinguinaliliohypogastric peripheral nerve block for analgesia after caesarean section," Journal of the Ramanujan Mathematical Society, vol. 15, no. 2, pp. 70-72, 2008.

[17] J. G. McDonnell, G. Curley, J. Carney et al., "The analgesic efficacy of transversus abdominis plane block after cesarean delivery: a randomized controlled trial," Anesthesia and Analgesia, vol. 106, no. 1, pp. 186-191, 2008.

[18] P. Bunting and I. McConachie, "Ilioinguinal nerve blockade for analgesia after caesarean section," British Journal of Anaesthesia, vol. 61, no. 6, pp. 773-775, 1988.

[19] E. Yucel, I. O. Kol, C. Duger, K. Kaygusuz, S. Gursoy, and C. Mimaroglu, "Ilioinguinal-iliohypogastric nerve block with intravenous dexketoprofen improves postoperative analgesia in abdominal hysterectomies," Brazilian Journal of Anesthesiology, vol. 63, no. 4, pp. 334-339, 2013.

[20] E. Naghshineh, S. Shiari, and M. Jabalameli, "Preventive effect of ilioinguinal nerve block on postoperative pain after cesarean section," Advanced Biomedical Research, vol. 4, p. 229, 2015 . 


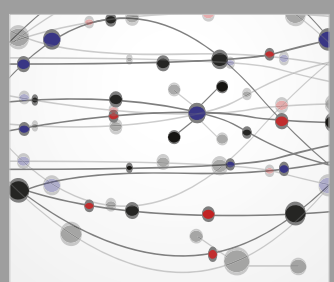

The Scientific World Journal
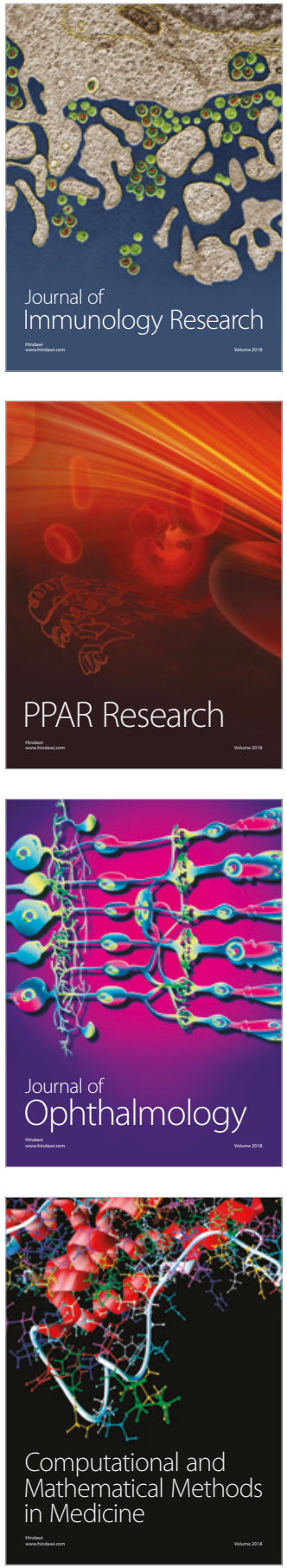

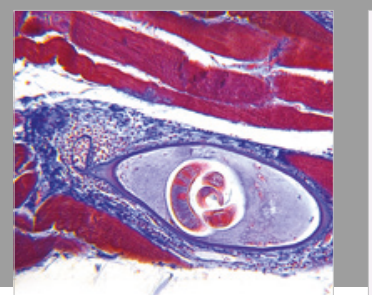

Gastroenterology Research and Practice

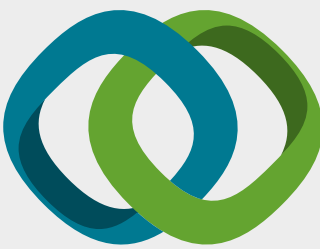

\section{Hindawi}

Submit your manuscripts at

www.hindawi.com
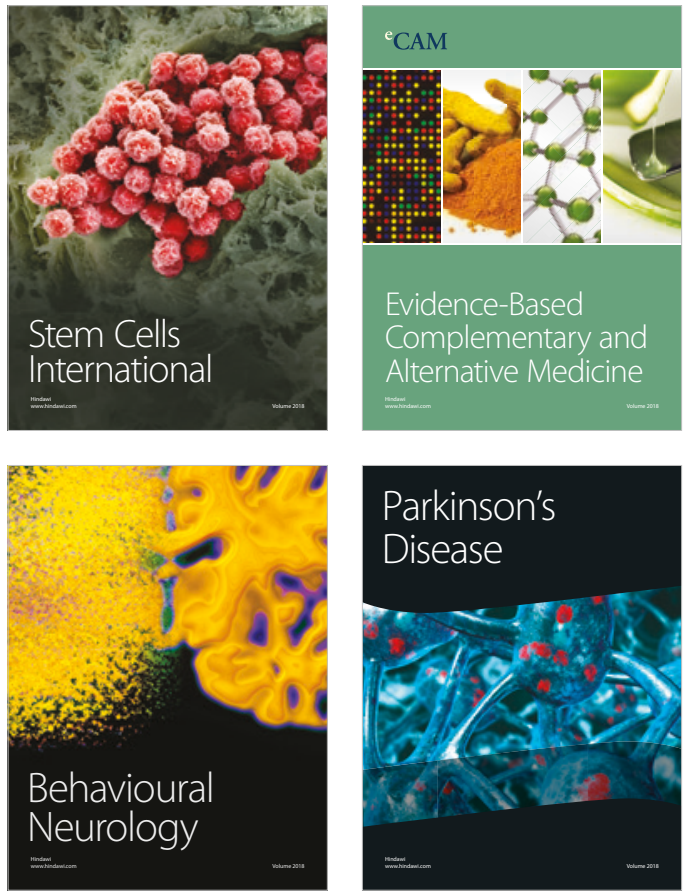

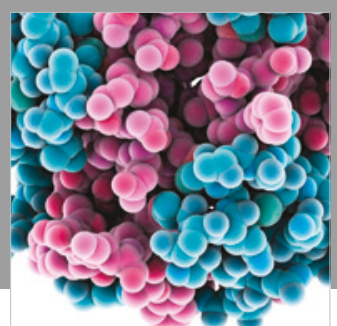

ournal of

Diabetes Research

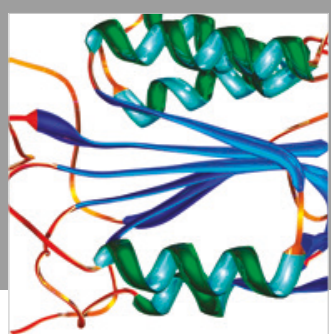

Disease Markers
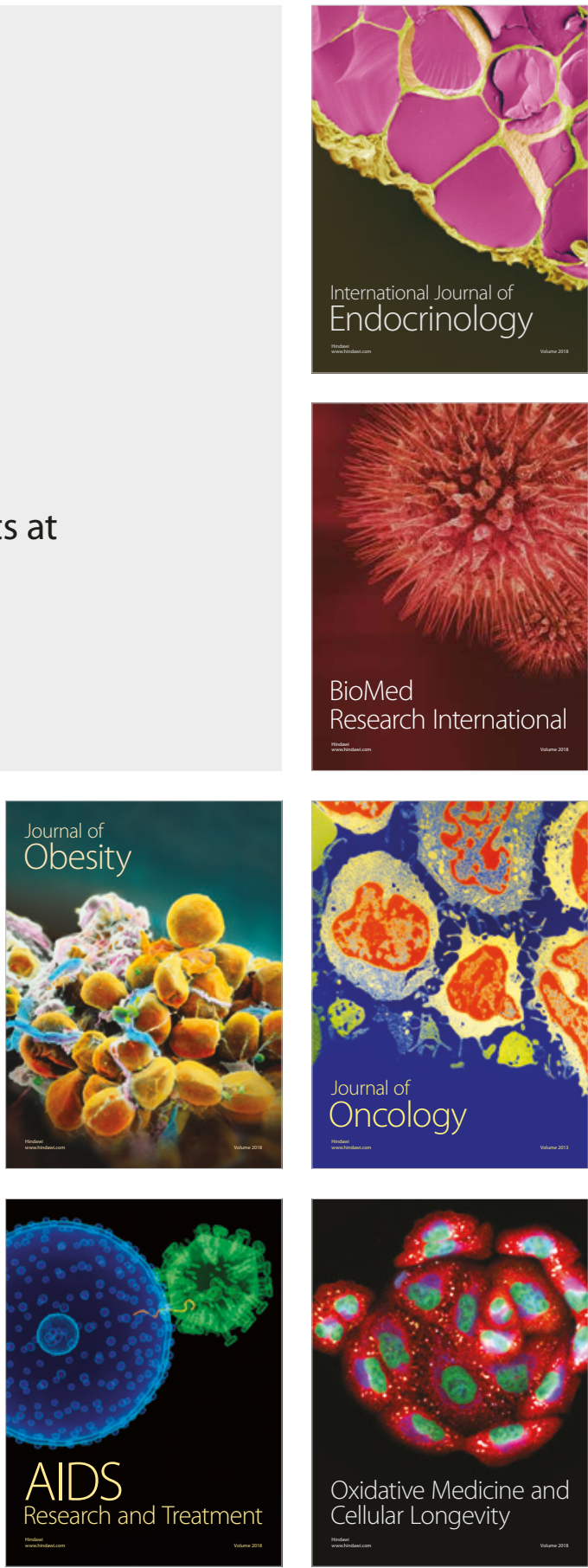